\title{
TRACING METAPHORS THROUGHOUT DESIGN EDUCATION
}

\author{
Koen VAN TURNHOUT' ${ }^{1}$, Christian KÖPPE ${ }^{2}$, Peter SCHUSZLER ${ }^{1}$ and René BAKKER ${ }^{1}$ \\ ${ }^{1}$ HAN University of Applied Sciences, Ruitenberglaan 26, 6802 CE, Arnhem \\ ${ }^{2}$ Utrecht University, Heidelberglaan 8, 3584 CS, Utrecht
}

\begin{abstract}
In this exploratory paper, we examine how students perceive metaphors for design research at first and subsequently assign more technical meanings to them throughout the programme. The use of metaphors can be a powerful didactic tool as metaphors can act as gateways, activating students' intuitions and existing knowledge, preparing the mental ground for newly acquired knowledge. However, if educational use of metaphors is studied empirically at all, it is usually at their first introduction and not for a longer period of time. Using a free-association exercise and open response questions in a questionnaire we examined how students' perception of a set of metaphors for design research changed during a 3-year programme. We found that metaphors get loaded with meaning through the aid of connecting concepts, which are important at first, but become less important over longer periods of time. Nevertheless, metaphors that are easily loaded with technical meaning at their first introduction also do better in the long term. As such a fair assessment of the long-term tenacity of the chosen metaphors can be made at the time of introduction.
\end{abstract}

Keywords: Research education, metaphors, DOT-Framework, inquisitiveness, triangulation first pedagogy

\section{INTRODUCTION}

Most teachers know the power of metaphor. A well-chosen metaphor can offer a gateway between the lived experience of students and the abstract and conceptual world many teachers are trying to bring across. Lakoff \& Johnson [1] have put forward the thesis that metaphorical thinking underlies most of our conceptual repertoire. In response, many authors have argued that teachers should pay careful attention to their uses of metaphor [2,3,4]. However empirical studies of the use of metaphors as a didactic device are rare [3] and often focus on the introduction of materials through metaphors, not on sustained use or on the way students give meaning to metaphors in the long run [4]. In contrast, we had the opportunity to investigate the long-lived use of a set of metaphors that were part of a framework, used throughout a four-year design and engineering programme. We had the chance to see how the metaphors of the framework were perceived at first and how they got loaded with technical meanings throughout the rest of the programme. In this paper, we will first sketch the educational context of the study and provide some background to the educational use of metaphors. Next, we present two exploratory studies to trace the meanings students assign to the metaphors in different stages of the programme.

\section{METAPHORS FOR DESIGN RESEARCH}

\subsection{Educational Context}

Our institution hosts design and engineering bachelor programmes with a professional orientation. This study focuses on our communication design programme. After a shared propaedeutic phase, students of this programme elect one of four majors: content design, experience design, interaction design or business media design. The four majors share an approach to teaching design research methods and their application to advance design project using the Development Oriented Triangulation (DOT)-Framework [5,6]. 
The DOT-Framework [6] was intended to be both accessible and rigorous so that we could teach it to first-year students, but it would remain to be of added value to students in the later stages of the study. To reach out to first-year students, it employs metaphors for five different research strategies: Library, Field, Lab, Workshop and Showroom. These strategies each relate to a set of design research methods with equal underlying goals. The Library strategy focuses on gaining an overview of existing work such as a literature search or a competitor analysis. Field-research helps to get an overview of the application context, for example through surveys or ethnography. With Lab-research one can test a design proposition in the application context, such as through a usability test or an A/B test. Showroom research helps to compare the design proposition with existing work, such as in a heuristic evaluation or peer-review. Workshop methods aim at (iteratively) exploring the innovation space, for example through ideation or morphological techniques. This choice of using metaphors (rather than technical jargon) for different elements of the framework was perceived as intuitive by teachers and students [5]; but some of the metaphors were considered to be more fitting than others, partly depending on the teachers' educational background. Earlier research also pointed out that the DOT-Framework was appreciated by students [5] and working with the DOT-Framework and its associated method-pack [7], increased students inquisitiveness [8].

\subsection{Metaphors in education}

Metaphors play an important role in the acquisition of new knowledge, as has been observed in science [9], cognition [1] and design [10,11]. Metaphors allow people to connect novel concepts to familiar ones. Krippendorff [10, p167] suggest metaphors mediate between two logically independent domains: the source domain and the target domain - for example human relationships and chemistry. Metaphors allow people to connect those by drawing resemblances between the domains. For example: the domains of 'chemistry' and 'love' share the notions of actors (molecules or people) that interact and may attract or repel one another. As such, the 'love is chemistry' metaphor, highlights these 'structural aspects' of love. Metaphors are effective in the transfer of what Lakoff and Johnson [1] have called entailments: patterns of understanding embedded in the vocabulary of the source, that help to reorganise knowledge in the target domain. Understanding love as chemistry entails seeing human relationships as the result of the interaction of intrinsic qualities of the actors. In prolonged use, the entailments are enforced, but the connection to the source domain becomes backgrounded; so over time, the metaphor does not feel like a metaphor anymore. In Krippendorff's terms: "Metaphors die in repeated use, but they leave behind the reality they had languaged into being $[9, \mathrm{p} 167]$ ".

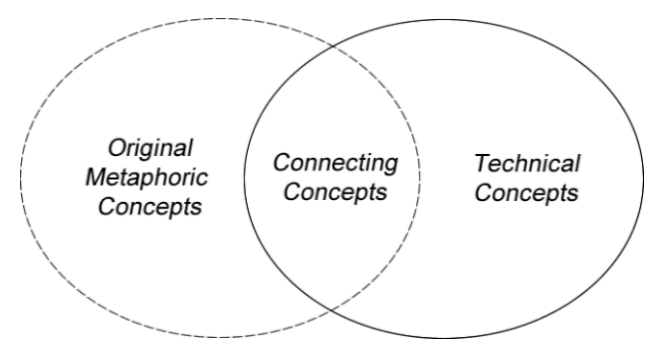

\section{Figure 1. Venn-diagram of metaphoric loading}

In figure 1, we illustrate the acquisition of new meaning through metaphors, with a somewhat simplified Venn-diagram. We assume that initially the use of metaphor will trigger and activate existing experience and concepts. The use of the Lab metaphor, for example, may trigger students to think of chemistry and glasswork. We refer to these as the original metaphoric concepts or metaphoric associations. Some of these concepts help to support students' understanding of the target domain. For example, the concepts of research, testing, and experimentation are familiar to students who have worked in a high school lab and will aid in the acquisition of the novel meaning of the Lab research strategy. In other words, we assume that these connecting concepts or associations serve as a support for the acquisition of technical concepts that were not part of the original knowledge base of the students, such as summative usability testing or validity. We use the notion of connecting concepts rather than the original notion of entailments, as we are not certain all connecting concepts carry structure and our study does not allow for distinguishing different types of connections between the metaphoric and the technical meaning. 


\section{STUDY 1: INTRODUCING THE DOT-METAPHORS}

\subsection{Data collection}

To get an idea of how students perceived the metaphors of the DOT-Framework at their first introduction, we executed a free association exercise in the introductory research course for $1^{\text {st }}$ years. Free associations can give some insights into the subjective experiences of students with regards to the educational materials [12]. At the end of a lesson, students were administered a handout of the poster of the DOT-Framework and asked to enlist the five first things that came to mind for each metaphor of the framework. We instructed them not to be selective in their responses by giving the example that if field research made them think of pink elephants, this was what they should write down. Each student fulfilled the exercise only once: each week of the course a different group of students was visited. The course was standardised, however, so all teachers were teaching the same materials and the results obtained in different groups could all be related to the same study programme.

In total 140 students completed the exercise, divided over eight weeks. The responses were digitised and corrected for misspellings and minor linguistic variations such as plural and singular forms. This led to a dataset of 3107 different associations, of which 1321 were unique, that could be examined both qualitatively and quantitatively. To aid quantitative evaluation associations were labelled as being either metaphoric, connecting or technical (see figure 1). Examples can be found in Table 1 on the next page. This classification should be treated with some care as the borders between the three categories are fuzzy, but it gives a rough indication of how the loading of the metaphor unfolded.

\subsection{Results}

Figure $2 \mathrm{a}$ enlists the relative number of metaphoric, connecting and technical associations. Figure $2 \mathrm{~b}$ gives the proportion of the sum of connecting and technical associations. On the horizontal axis, we outlined the course programme. The first week the framework was not yet introduced, followed by four lessons in the framework: a general introduction in week 2 and specific lessons on the Library and Showroom strategy in week 3, the Workshop and Lab strategy in week 4 and lessons on the Field and Library strategies in week 5. In this fifth week, the students also had to assemble a research plan using the strategies, which was executed in week 6 and 7 and presented in week 8 .
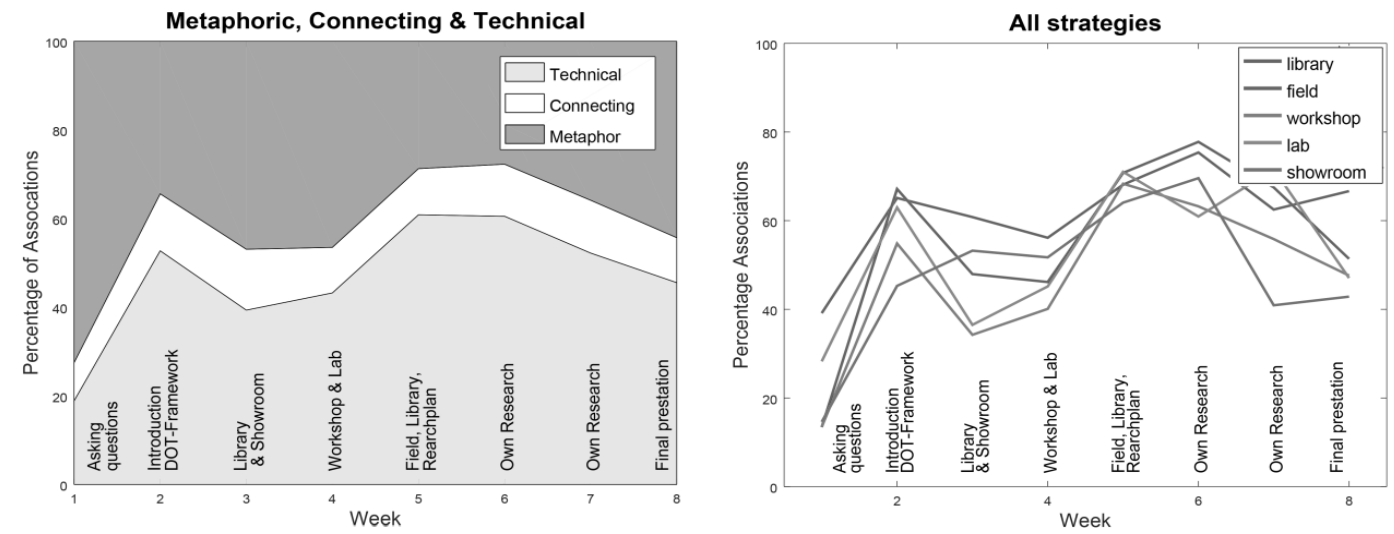

Figure 2. Relative number of metaphoric, connecting and technical associations related to the schedule of the introductory research course

Overall an increase of technical associations is seen throughout the course, although this is achieved mainly at two key points of the course. The first peak in the graph is immediately after the introduction of the framework in week 2. The gain of technical associations is lost to some extent in week 3 and 4, suggesting low retention of the novel content associations. One would expect Library and Showroom to do better in week 3 and Workshop and Lab in week 4, which is indeed the case, be it relative to the overall pattern of decline (Figure $2 b$ ). In week 5 a second peak is visible. Week 5 is when the research plan was to be assembled, using the DOT-Framework. In this week technical associations went up again, but during the execution weeks and the final presentation, there is another decline. Interestingly enough this pattern of peaks followed by decline is not visible for the bridging associations, possibly suggesting better retention of bridging concepts, compared to the technical concepts. 
From Figure 2 it is also visible that overall, Field, Library and Lab show bigger proportions of technical associations compared to Showroom and Workshop. This finding is confirmed in Table 1, which enlists the average proportion of metaphoric, connecting and technical, together with some examples of frequently reported associations.

Table 1. Relative number of different types of associations with examples

\begin{tabular}{|l|c|l|l|l|l|l|}
\multicolumn{1}{l|}{} & $\boldsymbol{\%}$ & Metaphoric & $\boldsymbol{\%}$ & Connecting & $\boldsymbol{\%}$ & Technical \\
\hline Library & 35 & Library, Silence & 13 & Books, Literature & 52 & Reading, Information, \\
& $\%$ & Shelves & $\%$ & Computer & $\%$ & Articles \\
\hline Field & 40 & Camping, Grass & 11 & Outside, People & 49 & Survey, Observation, \\
& $\%$ & Soccer & $\%$ & Contact & $\%$ & Practice \\
\hline Workshop & 51 & Fiddling, Scissors & 23 & Making, Building, & 26 & Improve, Develop, \\
& $\%$ & Wood & $\%$ & Creativity & $\%$ & Create \\
\hline Lab & 41 & Chemistry, Professor, & 17 & Testing, Research, & 42 & Prototype, Conclusion, \\
& $\%$ & Glasswork & $\%$ & Experiment & $\%$ & Measurement \\
\hline Showroom & 47 & Clothes, Cars & 23 & Showing, Exhibit & 30 & Positioning, Comparing \\
& $\%$ & Shop Display & $\%$ & Presenting, & $\%$ & Feedback \\
\hline
\end{tabular}

The Workshop and Showroom strategy count substantially less technical associations, more connecting associations and slightly more metaphoric associations. Assuming Workshop and Showroom are less familiar as a research strategy, the higher proportion of connecting associations is remarkable. An explanation could be that students try to make sense of the concept by actively seeking out connections between what they know of the metaphor and the technical notions that are conveyed. In this case, the concepts that connect both meanings are most salient and easily remembered. This finding is coherent with the earlier suggestion that bridging concepts may have better retention.

\section{STUDY 2: PROLONGED USE OF THE DOT-METAPHORS}

\subsection{Data collection}

The second study was part of our evaluation of the triangulation first pedagogy, reported in [8]. As part of this evaluation, a questionnaire was administered to students of the first three years, across the four different design majors. During the survey all students were in a $15 \mathrm{EC}$ project. After answering questions probing students' inquisitiveness and self-efficacy with regard to research and the use of the DOT-Framework, students were invited to answer five open response questions, one for each strategy of the framework. The question was: name three things you think of with respect to [name of strategy] research in your major. Students were able to skip these questions if they wanted to. Although this question was similar to the task in study 1, students were not invited explicitly to offer free associations, so the responses were more focussed towards the technical meanings. Nevertheless, as the study also involved first-year students we expected comparison to study 1 would be feasible.

A total of 210 students filled out the questionnaire of which 180 filled out the open response questions. Unlike in study 1 students often answered in short sentences. These were split into separate keywords. For example: "execute the test with a test application" was split into the keywords: "execute", "test" and "test application". Furthermore, differences in spelling and minor linguistic variations were corrected. This procedure led to a dataset of 3169 keywords, of which 1137 were unique.

\subsection{Results}

Figure $3 \mathrm{a}$ shows the relative occurrence of metaphoric, connecting and technical associations in the $1^{\text {st }}$, $2^{\text {nd }}$ and $3^{\text {rd }}$ year of the programme. The category of novel associations is added, for associations not captured in study 1 . Nearly all of these were technical, the majority methods of the CMD Methods pack [7] which was not in use during study 1 . In figure $3 \mathrm{~b}$ the relative number of technical associations (including the novel ones) per research strategy is depicted.

The transition between study 1 and study 2 can be attributed to the difference in the assignment for students. If students are no longer invited to report metaphoric associations the relative number of this type of associations goes down. Note that the first measurement point of study 2 was at the end of the first year, several weeks after the end of the research course of study 1. By now the research cards were introduced, accounting for most of the novel associations. 

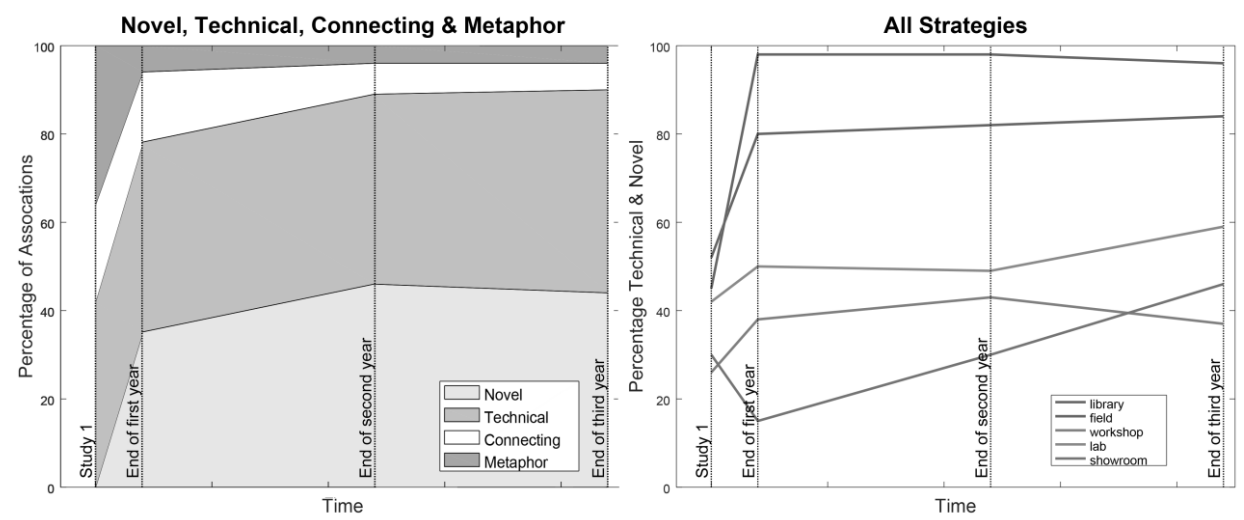

Figure 3. Relative number of novel, technical, connecting and metaphoric associations related to the 4-year study programme

Figure 3a further indicates a slight increase in novel associations and a stable amount of technical associations in the $2^{\text {nd }}$ and $3^{\text {rd }}$ year. Suggesting the technical meaning of the five strategies becomes more apparent for the students throughout the programme. Interestingly enough the amount of bridging associations is also decreasing. An explanation could be that these are no longer needed as a conceptual scaffold to the technical meanings. Like in study 1 the five research strategies do not score equally well: the Field, Lab, and Library strategy almost immediately reach a ceiling of around $85 \%$ technical associations, whereas showroom and workshop do not reach more than 50\%. Like in study 1 for these strategies the number of connecting associations is relatively high, although these strategies are also subject to the pattern of light decline shown in figure 3a. Possibly the metaphors of the Workshop and Showroom research strategy are less aptly chosen or, alternatively, the technical meaning is harder to learn. It may also be the case these strategies are taught less often, although this did not stand out in the study of teaching materials done earlier [8].

Overall the data of study 2 is in line with the general picture sketched at the beginning of the paper. A metaphor acts as a gateway to novel meanings by resemblances between the metaphor and the target meaning, but over time the metaphoric sense gets backgrounded. This finding can be corroborated by a qualitative analysis of the data of study 2 . In this analysis we focussed on the associations that were most common (over 10 mentions) and divided them into three groups: associations of which the proportion decreasing over the years, associations with constant proportions and associations with an increasing proportion in the later years. Table 2 list representative examples for all research strategies.

Table 2. Examples of association with decreasing, constant or rising proportions.

\begin{tabular}{|l|l|l|l|}
\hline & Decreasing & Constant & Rising \\
\hline Field & $\begin{array}{l}\text { People, Outside, Human } \\
\text { contact }\end{array}$ & Observe, Research, Analyse & $\begin{array}{l}\text { Interviews, Target group, } \\
\text { User }\end{array}$ \\
\hline Library & Search, Topic, Computer & $\begin{array}{l}\text { Books, Reading, Wikipedia, } \\
\text { Data }\end{array}$ & $\begin{array}{l}\text { Googling, Articles, } \\
\text { Literature }\end{array}$ \\
\hline Workshop & Hands-on, Fidgeting, Work & Building, Brainstorm, Ideas & $\begin{array}{l}\text { Prototyping, Sketching, } \\
\text { Making }\end{array}$ \\
\hline Showroom & $\begin{array}{l}\text { Research, Experiments, } \\
\text { Try-out }\end{array}$ & $\begin{array}{l}\text { Certainty, Measurement } \\
\text { Experimentation, }\end{array}$ & $\begin{array}{l}\text { Testing, Prototype, } \\
\text { Comparison }\end{array}$ \\
\hline
\end{tabular}

Although the differences can be subtle, the table suggests the more prominent associations become more specific (target group versus people; prototyping versus building), more disconnected from the metaphor (presentation versus show; articles versus books, experimentation versus experiments) and more anchored in the design profession (sketching versus ideas; testing versus experimentation) over time. In other words, the technical, professionally situated meaning of the research strategies is replacing the older metaphoric meanings. 


\section{DISCUSSION}

The study left us with somewhat of a paradox as not all metaphors 'performed' equally well. For Workshop and Showroom, technical meanings were harder to acquire at first - and this effect transcended throughout the whole study. Since the metaphoric sense of a technical term gets backgrounded over time, one would not expect it to be important in the long run. Yet it still seemed to operate behind the scenes. There may be alternative explanations for this finding, such as that students were taught less in Workshop and Showroom research, or that teachers were less sure about the technical meanings of these concepts. However, neither study 1 or the previous research about our educational programme revealed salient differences between Workshop and Showroom and the other metaphors in this respect. As such, the choice of metaphor may be the dominant factor here. If so, a careful choice of metaphor is essential, even if the metaphor is used for a long time. The upside of this finding is that one can decide quite early whether metaphors provide sufficient support for the technical meanings that need to be acquired.

\section{CONCLUSIONS}

In this paper, we have made an effort to trace the meanings students assigned to the design research strategies of the DOT-Framework in the course of a four-year design programme. We did this through a free association exercise in the introductory course and through investigating open response questions in a questionnaire in the rest of the curriculum. Earlier work [2] had shown that students found these metaphors intuitive; in the current study we have shed some light on a possible mechanism behind this finding. We found that connecting concepts: ideas that are shared between the metaphoric and the technical meaning of the strategies, played a role in the early perception and retention of the different research strategies. In particular for those research strategies that were less familiar to the students. As could be expected from the mechanisms outlined by Krippendorff [11], these connecting concepts became less critical over time. When their studies progressed, students reported less connecting associations and more technical, specific and professionally situated associations. In all, our findings suggest that the use of metaphor as a means to convey new meanings can reach out far beyond the conventional role of a first, and temporary, gateway to new knowledge.

\section{REFERENCES}

[1] Lakoff G.J. and Johnson M. Metaphors We Live By. 1980 (University of Chicago Press)

[2] Botha E. Why metaphor matters in education. South African Journal of Education 29.4, 2009

[3] Hankin R. Metaphors We Teach By. Dissertation Auckland University of Technology, 2017.

[4] Willox A.C., Harper S.L., Bridger D., Morton S., Orbach A. and Sarapura S. Co-Creating Metaphor in the Classroom for Deeper Learning: Graduate Student Reflections, International Journal of Teaching and Learning in Higher Education, 22(1), 2010, pp71-79.

[5] van Turnhout K., Coppens A., Craenmehr S. and Bakker R. Triangulation First: Teaching Research in a Multidisciplinary Design and Engineering Environment. Proceedings of the International Conference on Engineering and Product Design Education. 2016. Aalborg, Denmark.

[6] van Turnhout K., Bennis A., Craenmehr S., Holwerda R., Jacobs M., Niels, R., Zaad L., Hoppenbrouwers S., Lenior D. and Bakker R. Design patterns for mixed-method research in HCI. Proceedings of the 8th Nordic Conference on Human-Computer Interaction: Fun, Fast, Foundational, 2014, pp. 361-370. ACM.

[7] HAN University of Applied Sciences - Amsterdam University of Applied Sciences (2015). CMD Methods Pack. ISBN/EAN: 9990002057946. Available at: cmdmethods.nl.

[8] van Turnhout K., Köppe C., Schuszler P., Tankink T. and Bakker R. Research Education Nurtures Inquisitives of Professional Design and Engineering Students. In: Proceedings of the International Conference on Engineering and Product Design Education. 2018, London, UK.

[9] Hesse M.B. Models and Analogies in Science. 1966. University of Notre Dame Press, Indiana.

[10] Schön D.A. The reflective practitioner: How professionals think in action. 1987, Routledge.

[11] Krippendorff K. The semantic turn: A new foundation for design. crc Press, 2005.

[12] Hollway W. and Jefferson T. The free association narrative interview method. In: Given, Lisa M. ed. The SAGE Encyclopaedia of Qualitative Research Methods. 2008. Sage, pp. 296-315 